\title{
ANTHROPOMETRIC STUDIES IN PRE-SCHOOL CHILDREN IN NORTHEAST THAILAND ${ }^{1}$
}

\author{
Panata Migasena, D. I. Thurnham, Praneet Pongpaew, \\ Kanjana Hongthong, and Chamlong HaRinasuta \\ Department of Tropical Nutrition, Faculty of Tropical Medicine, Bangkok, Thailand
}

(Received January 28, 1974)

\begin{abstract}
In studies concerning the socio-economic development of the people in two villages in a resettlement area in Northeast Thailand, anthropometric methods, being used to study the nutritional status of preschool children, indicated that growth are below optimal by comparison with British standards. In comparison with local standards, growth rate was similar to that of healthy Thai children as determined in 1959 but below that of Bangkok kindergarten children (1969). The latter had growth rates similar to British standard whereas rural Thai children had growth rates similar to British children only in the first 10 to 12 months of life. Results from the anthropometric studies in determining nutritional status are compared with biochemical results. It was concluded that anthropometric measurements are easier to perform and yield information that agrees qualitatively with the general picture concerning nutritional status obtainable by biochemical methods.
\end{abstract}

We are now studying socio-economic development and nutritional status in two villages in the Northeast of Thailand (1). The first, Village 14 is one of a group of standard resettlement villages provided in Khon Kaen province by the government for people who were displaced by the building of Ubol Ratana Dam. These former predominantly rice-producing farmers are now farming jute and some cotton as their main sources of income. The second village, Non Bua Noy, is one of the original villages in the same area but outside the resettlement scheme where the people are mainly rice farmers. Both villages contain people who are typical of the area and whose ancestors for many generation have been engaged primarily in rice farming. Now the resettlement people are working on a cash-crop system under supervision of government and it will be interesting to see how their lives develop and change compared with the people in Non Bua Noy, the control village.

\footnotetext{
${ }^{1}$ Presented at the International Symposium on Criteria and Methodology for Assessment of Nutritional Status-Interpretation of Nutrition Survey Data, November 1970, Tokyo.
} 
Such changes as envisaged may or may not be rapid. It is possible however any changes that do occur may affect nutritional status. Over the last year, physical and biochemical parameters of nutritional status in the pre-school children in both villages have been studied. Children, under seven years of age, were chosen in this investigation as this section of the community is one of the first to show signs of nutritional deficiency and react most rapidly to changes in the diet (2).

\section{MATERIALS AND METHODS}

Anthropometric measurements (weight and height) were considered the simplest means of an assessing nutritional status. Measurement were made each month from children, under seven years of age, who could present a birth certificate in Resettlement Village 14 (68 children: 38 males and 30 females) but less frequently in Non Bua Noy (112 children: 54 males and 58 females). A growth curve calculated from the data as the mean of the group was compared with the growth curve for 365 children (221 males and 144 females) in a high class kindergarten school representing a well-to-do group in Bangkok.

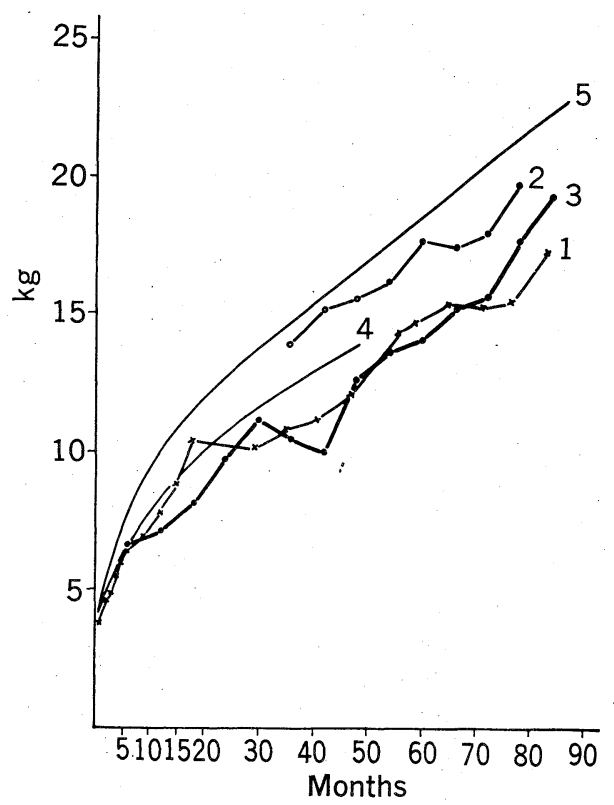

Fig. 1. Growth curves of Thai children boys-weight. 1. Resettlement Village 14 NE. Thailand. 2. Kindergarten school children, Bangkok. 3. Non Bua Noy, long established village, NE. Thailand. 4. 'Good' Thai children, Stahlie, 1959.5. British children, TANNER et al., 1966.

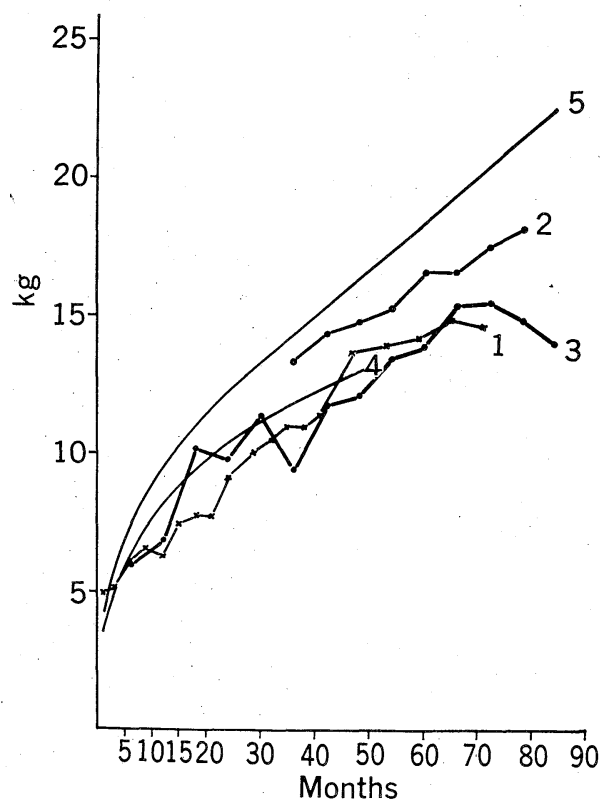

Fig. 2. Growth curves of Thai children girls-weight. 1. Resettlement Village 14, NE. Thailand. 2. Kindergarten school children, Bangkok. 3. Non Bua Noy, long established village, NE. Thailand. 4. 'Good' Thai children, Stahlie, 1959. 5. British children, TANNER et al., 1966. 


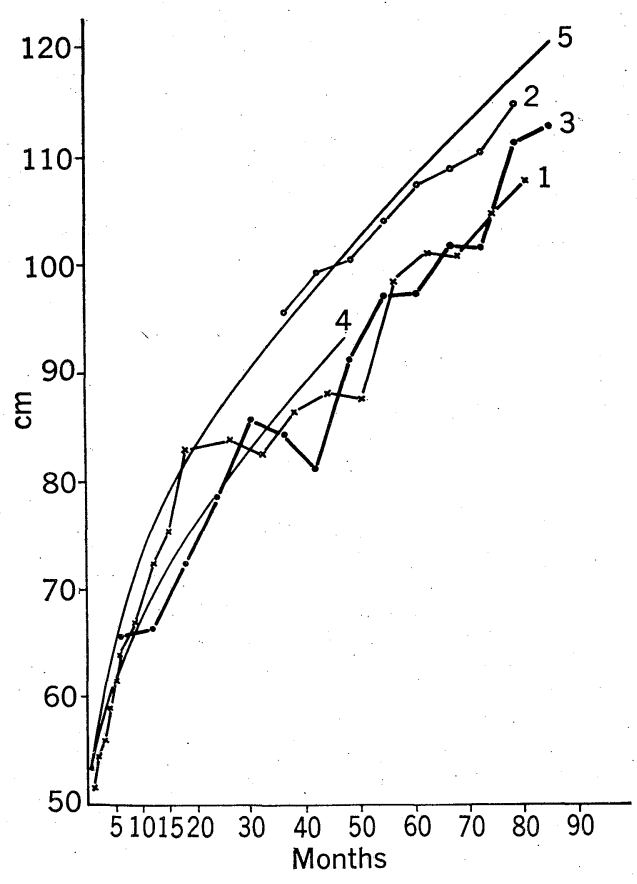

Fig. 3. Growth curves of Thai children boys-height. 1. Resettlement Village 14, NE. Thailand. 2. Kindergarten school children, Bangkok. 3. Non Bua Noy, long established village, NE. Thailand. 4. 'Good' Thai children, Stahlie, 1959. 5. British children, TANNER et al., 1966.

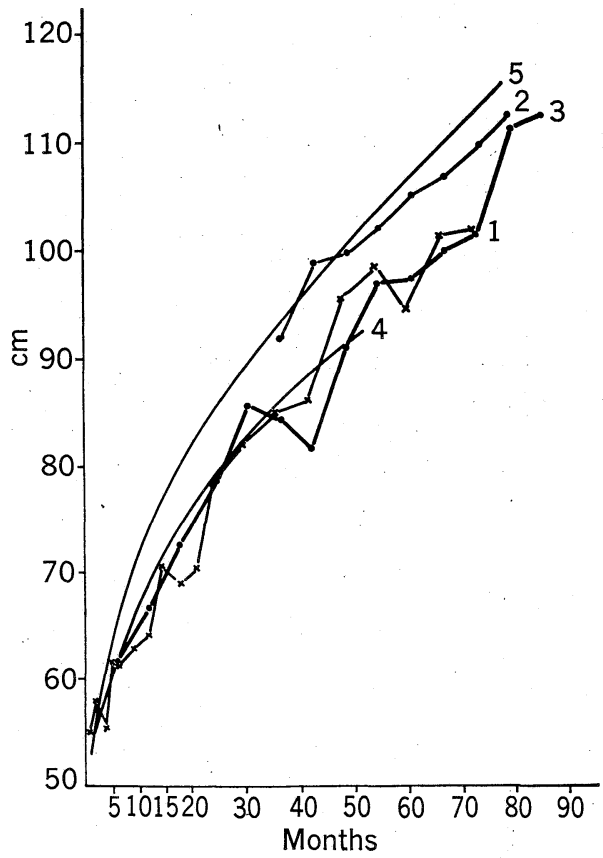

Fig. 4. Growth curves of Thai children girls-height. 1. Resettlement Village 14, NE. Thailand. 2. Kindergarten school children, Bangkok. 3. Non Bua Noy, long established village, NE. Thailand. 4. 'Good' Thai children, Stahlie, 1959. 5. British children, TANNER et al., 1966.

\section{RESULTS AND DISCUSSION}

The results of the growth curve calculated for 68 children in Resettlement Village 14, 112 children in Non Bua Noy and the 365 children in a high class kindergarten school in Bangkok as well as a 'good' group of Thai children surveyed in 1959 (3) and London children (4) are shown in Figs. 1, 2, 3 and 4.

From these results it was found that the growth rate of the children in Village 14 and those in Non Bua Noy were similar, but both were below that of the children in the Bangkok school. It is interesting that the growth rate of the children in Village 14 and Non Bua Noy was similar to the "good" group of Thai children survey in 1959 (3) while the Bangkok group had similar growth rates to those of London children reported by TANNER et al. (4). In these studies, rural Thai children showed a similar growth rate to British children only in the first 10 to 12 months of life. Above this age the growth curve was depressed by comparison with the Western children. The start of this depression coincides with the weaning age, 1-2 years.

The value of anthropometric studies can readily be assessed if we look 
briefly to some of the biochemical parameters that have been studied in these children. When first investigated the children were found to be very anaemic, $90 \%$ having MCHC values below 30 (5). Plasma albumin levels, however, were found to be within the control range, 3.7 to $5.3 \mathrm{~g}$ per $100 \mathrm{ml}$ (mean $=4.4 \pm 0.5$ ), and only four children out of the sixty-one had albumin levels below this range. The mean value for plasma urea found in the children in Resettlement Village 14 was $8.4 \pm 2.8$ ( 65 children) $\mathrm{mg}$ per $100 \mathrm{ml}$ of plasma. This value was significantly lower $(p=0.001)$ than that found in Bangkok orphanage children of the same age group where the level was $10.6 \pm 2.2$ (48 children). The Bangkok orphanage children represent the ordinary class of people in Bangkok. It is interesting to note that the mean values for plasma urea for the different age groups of children was higher than that of the babies in Village 14. Mean for babies below 2 years of age was $6.5 \pm 2.7$ ( 19 children) while plasma from those children between 2 and 7 years gave a mean value of $9.24 \pm 3.0$ ( 46 children). The difference between these two groups was not significant but by comparison with the Bangkok orphanage children $(10.6 \pm 2.2)$ the plasma urea levels of the young village children suggest that their diet may not contain adequate protein which was also supported by the dietary survey (Table 1).

The urine hydroxyproline: Creatinine index values of the pre-school children in the two villages were also studied. In Village 14, 54\% were below 2.0 and $20 \%$ below 1.5, while in Non Bua Noy $42 \%$ below 2.0 and $22 \%$ below 1.5 . According to WhITEHEAD (6) an index value lower than 2.0 indicates marginal malnutrition. If this is true, then approximately $50 \%$ of the children in both villages were malnourished. Such findings are possibly supported by the plasma urea data and also dietary survey (Table 1) that indicate a low protein intake. In addition it has been found that there is a high proportion of riboflavin deficiency indicating further dietary inadequacy (7).

WHITEHEAD (6) also suggested that individuals with an index value below 1.5 often shows sign of clinical malnutrition. But this was not the case in the children in the current survey since a large number had indices in this range but none was clinically malnourished. This difference may be a result of some racial element as WHITEHEAD (6) was working with Africans or possibly a result of differences in the main staple intake, cassava $v s$ rice (8).

From the above it can be seen that interpretation of biochemical data can often be difficult and give conflicting ideas. For example plasma albumin level indicated a healthy normal group while urine hydroxyproline: creatinine indices indicated considerable borderline malnutrition. Taking all the biochemical data together, it is indicated possibly that there is dietary, inadequacy of various nutrients which was confirmed by dietary survey (Table 1). Nevertheless, there is no acute or severe malnutrition at the moment. Such information was much more simply obtained from the anthropometric measurements. The latter indicated that growth rate was below optimal by Western standards but was satisfactory when 


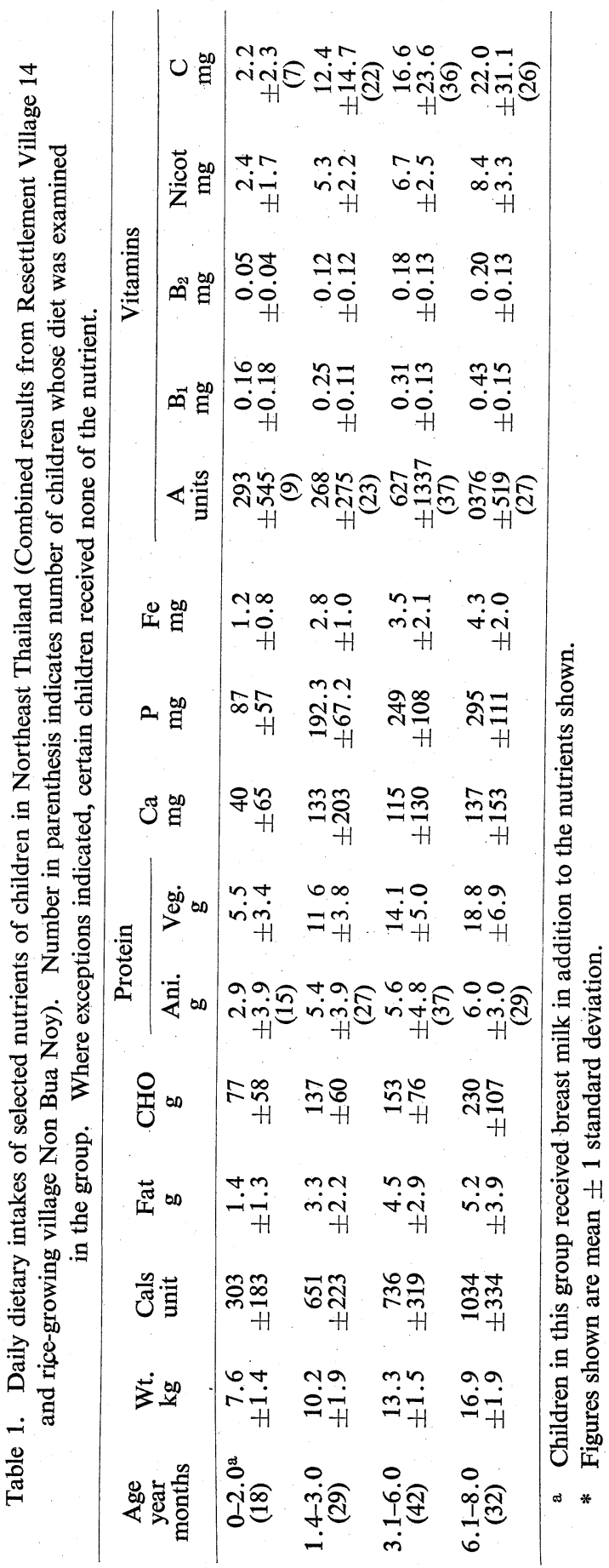


compared with local standards which indirectly indicated that there were no acute nutritional problem at present.

Both anthropometric and biochemical data suggest therefore that malnutrition is not an acute problem but possibly a chronic problem that may affect large numbers of the pre-school children in Northeast Thailand. Clinical signs of malnutrition are rarely observed but the existing state of under nourishment is a potential source of danger particularly in small children, when complicated by superimposed infection, eg. gastro-intestinal or respiratory disease, typical signs of severe malnutrition may result.

The anthropometric results suggest when compared with those of STAHLIE (3) that the nutritional status of rural Thai children, in the two villages studied, is better than was found from Thai children generally ten years ago. The high growth rate of the Bangkok kindergarten children, possibly suggests that nutritional factors may play a more important part than genetic factors in determining the growth rate in rural children early in life. Thus poor nutrition in pre-school years may be major factor contributing to the small stature of Thai people.

From these studies it is seen that anthropometric method can given useful information concerning the nutritional status. The techniques are easily used by personnel who only require a short period of training. Personnel such as nurses, medical or technical staff are very suitable for such work where a large population has to be screened to provide information to solve nutritional and public health problems.

We thank Mrs. N. Vudhivai, Mrs. S. Changbumrung and Mr. S. Egoramaiphol for their excellent technical assistance and are indebted to Dr. S. Cheunchusin and Dr. U. Katesing, respectively, for allowing us to work at the orphanage and kindergarten. The authors are very grateful to the British and Japanese Governments for equipment supplied under Colombo Plan and for a grant from SEAMEO Regional Project for Tropical Medicine and Public Health to carry out this study.

\section{REFERENCES}

1) Migasena, P., Thurnham, D. I., Pongpaew, P., Jintakanon, K., and Harinasuta, C., Proceeding of First Southeast Asia Region Seminar on Nutrition, Jakarta, 1969, p. 82 (1971).

2) Jelliffe, D. B., W. H. O. Monograph, Series No. 53; p. 178 (1966).

3) Stahlie, T. D., Thai children under four, Groesbeck-Assenbroek Foundation publishing supporter, Amsterdam: published privately (1959).

4) Tanner, J. M., Whitehouse, R. H. and Takaishi, M., Arch. Dis. Childh., 41, 613 (1966).

5) Thurnham, D. I., Migasena, P., Pongpaew, P., Jintakanon, K., and Pavapootanon, N., Proceeding of First Southeast Asian Region Seminar on Nutrition, Jakarta, 1969, p. 68 (1971).

6) Whitehead, R. G., Lancet, 2, 567 (1965).

7) Thurnham, D. I., Migasena, P., and Pavapootanon, N., Mikrochimica Acta, 5, 998 (1970).

8) Migasena, P., Viseshakul, D., Changbumrung, S., and Harinasuta, C., Southeast Asian J. Trop. Med. Pub. Hlth., 2, 399 (1971). 